\title{
New conditions for independence of events
}

DOI:

10.1080/0020739X.2018.1478133

\section{Document Version}

Accepted author manuscript

Link to publication record in Manchester Research Explorer

\section{Citation for published version (APA):}

Hou, J., \& Nadarajah, S. (2018). New conditions for independence of events. International Journal of Mathematical Education in Science and Technology, 1-3. https://doi.org/10.1080/0020739X.2018.1478133

\section{Published in:}

International Journal of Mathematical Education in Science and Technology

\section{Citing this paper}

Please note that where the full-text provided on Manchester Research Explorer is the Author Accepted Manuscript or Proof version this may differ from the final Published version. If citing, it is advised that you check and use the publisher's definitive version.

\section{General rights}

Copyright and moral rights for the publications made accessible in the Research Explorer are retained by the authors and/or other copyright owners and it is a condition of accessing publications that users recognise and abide by the legal requirements associated with these rights.

\section{Takedown policy}

If you believe that this document breaches copyright please refer to the University of Manchester's Takedown Procedures [http://man.ac.uk/04Y6Bo] or contact uml.scholarlycommunications@manchester.ac.uk providing relevant details, so we can investigate your claim.

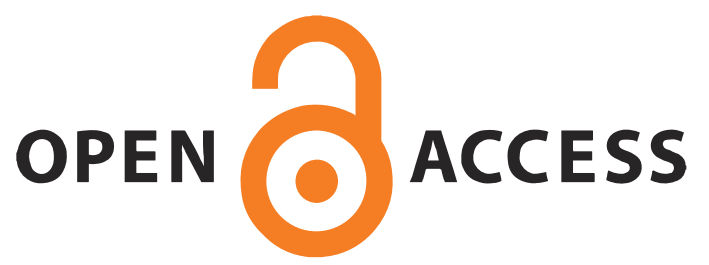




\title{
New conditions for independence of events
}

by

Juncheng Hou and Saralees Nadarajah

School of Mathematics, University of Manchester, Manchester M13 9PL, UK

\begin{abstract}
It is well known that two events $A$ and $B$ are independent if and only if $P(A B)=$ $P(A) P(B)$. Here we derive a condition for independence not well known. We then extend the condition for independence of $n$ events.
\end{abstract}

Keywords: Complement, Generalization, Intersection

\section{Introduction}

Suppose $A$ and $B$ are two events. Standard undergraduate textbooks (for example, Bertsekas and Tsitsiklis (2002)) give the following conditions for independence $A$ and $B: P(A B)=P(A) P(B)$, where $A B$ denotes the intersection of $A$ and $B ; P(A \mid B)=P(A)$, where $P(A \mid B)$ denotes the probability of $A$ conditioned on $B ; P(B \mid A)=P(B)$, where $P(B \mid A)$ denotes the probability of $B$ conditioned on $A$. by $\frac{A}{A}$.

A condition for independence not well known is the following. We denote the complement of $A$

Proposition $1 A$ and $B$ are independent if and only if

$$
P(A \bar{B}) P(B \bar{A})=P(A B)\{1-P(B)-(A \bar{B})\}
$$

or equivalently

$$
P(A \bar{B}) P(B \bar{A})=P(A B) P(\overline{A B}) .
$$

Proof: Note that

$$
\begin{aligned}
& P(A) P(B)=P(A B) \\
\Longleftrightarrow & {[P(A B)+P(A)-P(A B)][P(A B)+P(B)-P(A B)]=P(A B) } \\
\Longleftrightarrow & P(A B) P(B)+[P(A)-P(A B)][P(A B)+P(B)-P(A B)]=P(A B) \\
\Longleftrightarrow & P(A B) P(B)+P(A B)[P(A)-P(A B)]+P(A)-P(A B)][P(B)-P(A B)]=P(A B) \\
\Longleftrightarrow & {[P(A)-P(A B)][P(B)-P(A B)]=P(A B)\{1-P(B)-[P(A)-P(A B)]\} } \\
\Longleftrightarrow & P(A \bar{B}) P(B \bar{A})=P(A B)\{1-P(B)-(A \bar{B})\} .
\end{aligned}
$$

The result follows.

The condition (2) has been noted before in the last four lines in Section 2 of Joarder and Al-Sabah (2002). The condition (1) appears to be new. 
The aim of this note is to generalize Proposition 1. Section 2 generalizes it for $n$ events. Section 3 notes some particular cases of the result of Section 2.

\section{Main result}

Suppose there are $n$ events. For simplicity of notation, let $P(i), i=1,2, \ldots, n$ denote the probability that the $i$ th event occurs. Let $V=P(123 \cdots n)$ denote the probability of the intersection of the $n$ events. Let $\widetilde{P}(i)=P(i)-V$ for $i=1,2, \ldots, n$.

Theorem 1 generalizes Proposition 1 for $n$ events.

Theorem 1 With the notation as above, the $n$ events are independent if and only if

$$
\begin{gathered}
\widetilde{P}(1) \widetilde{P}(2) \cdots \widetilde{P}(n)=V\{1-P(2) P(3) \cdots P(n)-\widetilde{P}(1) P(3) P(4) \cdots P(n) \\
-\widetilde{P}(1) \widetilde{P}(2) P(4) P(5) \cdots P(n)-\cdots-\widetilde{P}(1) \widetilde{P}(2) \cdots \widetilde{P}(n-1)\} .
\end{gathered}
$$

Proof: Note that

$$
\begin{aligned}
& P(1) P(2) P(3) \cdots P(n)=V \\
& \Longleftrightarrow \quad[V+P(1)-V][V+P(2)-V] \cdot[V+P(n)-V]=V \\
& \Longleftrightarrow V P(2) P(3) \cdots P(n)+[P(1)-V][V+P(2)-V] P(3) P(4) \cdots P(n)=V \\
& \Longleftrightarrow V P(2) P(3) \cdots P(n)+V[P(1)-V] P(3) P(4) \cdots P(n) \\
& +[P(1)-V][P(2)-V][V+P(3)-V] P(4) P(5) \cdots P(n)=V \\
& \vdots \\
& \Longleftrightarrow V P(2) P(3) \cdots P(n)+V[P(1)-V] P(3) P(4) \cdots P(n) \\
& +V[P(1)-V][P(2)-V] P(4) P(5) \cdots P(n)+\cdots \\
& +V[P(1)-V][P(2)-V] \cdots[P(n-2)-V] P(n) \\
& +[P(1)-V][P(2)-V] \cdots[V+P(n)-V]=V \\
& \Longleftrightarrow V P(2) P(3) \cdots P(n)+V[P(1)-V] P(3) P(4) \cdots P(n) \\
& +V[P(1)-V][P(2)-V] P(4) P(5) \cdots P(n)+\cdots \\
& +V[P(1)-V][P(2)-V] \cdots[P(n-2)-V] P(n) \\
& +V[P(1)-V][P(2)-V] \cdots[P(n-1)-V] \\
& +[P(1)-V][P(2)-V] \cdots[P(n)-V]=V \\
& \Longleftrightarrow \quad[P(1)-V][P(2)-V] \cdots[P(n)-V]=V\{1-P(2) P(3) \cdots P(n) \\
& -[P(1)-V] P(3) P(4) \cdots P(n)-[P(1)-V][P(2)-V] P(4) P(5) \cdots P(n)-\cdots \\
& -[P(1)-V][P(2)-V] \cdots[P(n-1)-V]\} \text {. }
\end{aligned}
$$

Hence the result. 


\section{Particular cases}

Here, we state particular cases of Theorem 1 for $n=2,3,4$. When $n=2$, Theorem 1 reduces to

$$
\widetilde{P}(1) \widetilde{P}(2)=P(12)\{1-P(2)-\widetilde{P}(1)\},
$$

which is equivalent to Proposition 1. When $n=3$, Theorem 1 reduces to

$$
\widetilde{P}(1) \widetilde{P}(2) \widetilde{P}(3)=P(123)\{1-P(2) P(3)-\widetilde{P}(1) P(3)-\widetilde{P}(1) \widetilde{P}(2)\} .
$$

Finally, when $n=4$, Theorem 1 reduces to

$\widetilde{P}(1) \widetilde{P}(2) \widetilde{P}(3) \widetilde{P}(4)=P(1234)\{1-P(2) P(3) P(4)-\widetilde{P}(1) P(3) P(4)-\widetilde{P}(1) \widetilde{P}(2) P(4)-\widetilde{P}(1) \widetilde{P}(2) \widetilde{P}(3)\}$

\section{Acknowledgments}

The authors would like to thank the Editor and the referee for careful reading and comments which improved the paper.

\section{References}

[1] Bertsekas, D. P. and Tsitsiklis, J. N. (2002). Introduction To Probability. Athena Scientific, New York.

[2] Joarder, A. H. and Al-Sabah, W. S. (2002). The dependence structure of conditional probabilities in a contingency table. International Journal of Mathematical Education in Science and Technology, 33, 475-480. 